\title{
Fatores de risco para infecções no trato urinário: revisão integrativa
}

\author{
Risk factors for urinary tract infections: integrative review \\ Factores de riesgo de infecciones del tracto urinario: revisión integral
}

Pedro Paulo Assunção da Silva ${ }^{1 *}$, Yana Balduíno de Araújo', Grace Kelly Gomes Leal ${ }^{1}$, José da Silva Júnior².

\begin{abstract}
RESUMO
Objetivo: Analisar fatores de risco para infecções no trato urinário. Métodos: Tratou-se de uma revisão integrativa de literatura, realizada através de dados obtidos das bases Biblioteca Virtual de Saúde (BVS) e PubMed, tendo como critérios de inclusão artigos científicos, publicados entre 2010 a 2020, e realizados com seres humanos maiores de dezoito anos. Já os critérios de exclusão foram outras formas de publicação que não fossem artigos científicos, que ultrapassassem o período de dez anos de publicação (2010 a 2020), realizados com animais, in vitro ou com pessoas menores de dezoito anos. Resultados: Foram selecionados 10 artigos na base de dados BVS e 5 na Pubmed. As infecções do trato urinário apresentam múltiplas causas e fatores de risco, sendo grande parte deles relacionados à falta de higiene adequada na região genital, contaminação por microrganismos e alterações hormonais. Considerações finais: Os principais fatores de risco evidenciados foram o uso de cateteres vesical, as práticas sexuais desprotegidas, infecção genital previa, resistência a antibióticos, falta ou excesso de higiene nas áreas genitais, anatomia da uretra, hiperglicemia e alterações hormonais.
\end{abstract}

Palavras-chave: Pacientes, Fatores de risco, Infecções do trato urinário.

\begin{abstract}
Objective: To analyze risk factors for urinary tract infections. Methods: This was an integrative literature review, carried out using data obtained from the Virtual Health Library (BVS) and PubMed databases, with the inclusion criteria of scientific articles, published between 2010 and 2020, and carried out with human beings older than eighteen years. The exclusion criteria were forms of publication other than scientific articles, which exceeded the period of ten years of publication (2010 to 2020), carried out with animals, in vitro or with people under eighteen years. Results: We selected 10 articles in the BVS database and 5 in Pubmed. As treatment infections present multiple causes and risk factors, a large part of them being related to lack of adequate hygiene in the genital region, contamination by microorganisms and hormonal alterations. Final considerations: The main risk factors evidenced for the use of bladder catheters, unprotected sexual practices, previous genital infection, resistance to antibiotics, lack or excess of hygiene in genital areas, urethral anatomy, hyperglycemia and hormonal alterations.
\end{abstract}

Keywords: Patients, Risk factors, Urinary tract infections.

\begin{abstract}
RESUMEN
Objetivo: Analizar los factores de riesgo de infecciones del tracto urinario. Métodos: Se realizó una revisión integradora de la literatura, realizada con datos obtenidos de la Biblioteca Virtual en Salud (BVS) y bases de datos PubMed, con los criterios de inclusión de artículos científicos, publicados entre 2010 y 2020 , y realizada con seres humanos mayores de dieciocho años. Los criterios de exclusión fueron las formas de publicación distintas de los artículos científicos, que superaron el plazo de diez años de publicación (2010 a 2020), realizadas con animales, in vitro o con personas menores de dieciocho años. Resultados: Se seleccionaron 10 artículos en la base de datos BVS y 5 en Pubmed. Como tratamiento las infecciones presentan múltiples causas y factores de riesgo, gran parte de ellos están relacionados con falta de higiene adecuada en la región genital, contaminación por microorganismos y alteraciones hormonales. Consideraciones finales: Los principales factores de riesgo evidenciados por el uso de sondas vesicales, prácticas sexuales sin protección, infección genital previa, resistencia a antibióticos, falta o exceso de higiene en áreas genitales, anatomía uretral, hiperglucemia y alteraciones hormonales.
\end{abstract}

Palabras clave: Pacientes, Factores de riesgo, Infecciones urinarias.

1 Faculdade de Ciências Médicas da Paraíba, João Pessoa - PB. *E-mail: pedroassuncaopaulo@gmail.com

2 Universidade Federal do Maranhão, Imperatriz - MA.

SUBMETIDO EM: 11/2020

ACEITO EM: 12/2020

PUBLICADO EM: 1/2021 


\section{INTRODUÇÃO}

O corpo humano é formado por um conjunto de tecidos e órgãos que formam sistemas. A interação desses sistemas é responsável pelo bom funcionamento do organismo, e cada um deles possuem funções importantes para a manutenção da vida, especialmente os sistemas de órgãos vitais como o cerebral, o cardiovascular, e o renal (BORGES AA, et al., 2014). O sistema urinário é composto por rins, ureteres, bexiga e uretra, sendo responsável pela excreção de líquidos e de partículas residuais das células, que podem causar toxicidade ao corpo se não forem adequadamente eliminadas através da urina, além de regular o volume e composição química do sangue (DIAS IOV, et al., 2015).

A infecção do trato urinário (ITU) consiste na proliferação de microrganismos no trato urinário. Normalmente já existem microrganismos no trato urinário, todavia algumas situações podem acarretar em uma proliferação exacerbada deles ou a infecções de outros microrganismos patógenos, contribuindo para a instalação de uma ITU (RAMOS GC, et al., 2016). A ITU é um quadro infeccioso muito prevalente entre a população mundial, e estima-se que $86 \%$ das pessoas já tenham sofrido com alguma ITU ao longo da vida, especialmente a população feminina, devido a sua anatomia uretral ser mais curta que o comprimento da uretra masculino, e consequentemente os patógenos podem colonizar mais facilmente a bexiga e o espaço uretral (CASTRO FILHO CAS, et al., 2013).

Os hábitos de vida e higiene estão relacionados ao surgimento de ITU. Em países subdesenvolvidos como a Angola, a população por ter menos acesso ao saneamento básico e as informações de saúde têm provavelmente $53 \%$ de chances de contraírem o quadro infecioso do que a população de países desenvolvidos como a Inglaterra, que a população tem mais acesso à educação em saúde, e as ações e serviços de promoção e proteção da saúde (ERCOLE FF, et al., 2013).

No Brasil estima-se que $73 \%$ da população tenha contraído ITU, tal fator é preocupante, pois essa infecção pode resultar em complicações como danos permanentes aos rins, predisposição para complicações gestacionais e sepse (NASCIMENTO WL, et al., 2015). Diante do exposto foi formulada a seguinte questão norteadora: Quais evidências cientificas existentes na literatura acerca dos fatores de risco para infecções no trato urinário? O objetivo geral desse estudo foi: Analisar fatores de risco para infecções no trato urinário.

\section{MÉTODOS}

O presente estudo se tratou de uma revisão integrativa de literatura. Este tipo de método foi escolhido por possibilitar a síntese e análise do conhecimento científico já produzido sobre a temática: Fatores de risco para infecções no trato urinário. Para a localização dos estudos relevantes, que correspondessem a questão norteadora da pesquisa, foi utilizado descritores indexados nos idiomas português, inglês e espanhol obtidos nos Descritores em Ciências da Saúde (DeCS), sendo esses: Pacientes; Patients; Fatores de risco; Risk Factors; Factores de Riesgo; Infecções do Trato Urinário; Urinary Tract Infections; Infecciones Urinarias. Tais descritores foram combinados com o operador lógico booleano AND que definiu a relação de adição entre os termos escolhidos, e assim a busca de arquivos teve a combinação de todos os descritores, com o propósito de encontrar artigos relacionados a temática.

As bases de dados utilizadas para a busca de artigos foram a BVS e PubMed. Para delimitar a busca de artigos aos objetivos desse trabalho foram utilizados critérios de inclusão e exclusão, sendo que os critérios de inclusão foram: artigos científicos disponíveis na integra, publicados nos últimos dez anos (2010 a 2020), e estudos realizados com seres humanos maiores de dezoito anos de idade. Já os critérios de exclusão foram: Outras formas de publicação que não fossem artigos científicos, artigos científicos incompletos, artigos que ultrapassassem o período dos dez últimos anos de publicação (2010 a 2020), e estudos realizados com animais, in vitro ou que envolvessem pessoas menores de dezoito anos de idade.

A análise para seleção e organização dos dados dos estudos foi realizada em duas fases, sendo que na primeira, os estudos foram pré-selecionados segundo os critérios de inclusão e exclusão, e foram descartados aqueles que após a leitura seletiva não estavam de acordo com a temática abordada. 
Assim se obteve cento e vinte (120) estudos como busca geral na base de dados da BVS, sendo que limitando a busca para artigos com texto completo realizado com humanos nos últimos cinco anos obtiveramse dezenove (19) estudos, destes após a leitura seletiva na integra apenas dez (10) estudos foram condizentes com a questão desta pesquisa.

$\mathrm{Na}$ base de dados da PUBMED, na busca total foram encontrados vinte (20) estudos, aplicando na pesquisa o filtro que limita por texto completo dos últimos cinco anos com humanos, obtiveram-se seis (06) estudos, destes após a leitura seletiva na integra cinco (05) estudos foram selecionados.

$\mathrm{Na}$ segunda fase de organização dos dados dos artigos selecionados para comporem essa revisão bibliográfica, esses tiveram seus objetivos e principais resultados destacados em quadro sinóptico com a finalidade de identificar os achados de todos os autores e assim terem seus conteúdos visualizados de maneira mais fácil pelos leitores. Para classificar o nível de evidência de cada artigo selecionado, foi utilizada a classificação do Centro de Medicina Baseada em Evidência de Oxford (Quadro 1).

Quadro 1 - Nível de evidência segundo a classificação do Centro de Medicina Baseada em Evidência de Oxford, $\mathrm{n}=15$.

\begin{tabular}{|c|c|l|}
\hline $\begin{array}{c}\text { Grau de } \\
\text { recomendação }\end{array}$ & $\begin{array}{c}\text { Nível de } \\
\text { evidência }\end{array}$ & \multicolumn{1}{c|}{ Descrição } \\
\hline \multirow{4}{*}{ A } & $1^{\underline{a}}$ & Revisão sistemática de ensaios clínicos controlados randomizado. \\
\cline { 2 - 3 } & 1B & Ensaio clínico controlado randomizado com intervalo de confiança estreito \\
\cline { 2 - 3 } & 1C & Resultados terapêuticos \\
\hline \multirow{4}{*}{ B } & $2^{\underline{a}}$ & Revisão Sistemática de Estudos de Coorte \\
\cline { 2 - 3 } & 2B & Estudo de Coorte \\
\cline { 2 - 3 } & 2C & Observação de resultados terapêuticos \\
\cline { 2 - 3 } & $3^{\text {a }}$ & Revisão Sistemática de Estudos Caso-Controle \\
\hline C & 3B & Estudo Caso-Controle \\
\hline D & 4 & Relato de Casos \\
\hline
\end{tabular}

Fonte: Silva PPA, et al., 2020. Baseado em Oxford, 2009.

\section{RESULTADOS E DISCUSSÃO}

De acordo com os objetivos desse trabalho, os resultados e discussão foram subdivididos em tópicos para melhor explanação da temática sendo eles: Fatores de risco para infecção no trato urinário; principais sintomas e métodos diagnósticos para identificar as infecções no trato urinário; Tratamentos para as infecções no trato urinário. O primeiro tópico por apresentar o foco principal desse trabalho, conta com um quando sinóptico para identificar os autores e ano de publicação que foram selecionados para compor essa revisão de literatura.

\section{Fatores de risco para infecção no trato urinário}

Os principais fatores de risco para infecções no trato urinário (ITU) identificados foram relacionados ao uso de cateteres vesical, especialmente os de demora, práticas sexuais desprotegidas, aumento da idade, urina com pH alcalino, infecção genital, resistência a antibióticos, má higienização das regiões perianal e vaginal ou excesso de higiene nessas áreas, diabetes mellitus e a hiperglicemia, e mulheres pois essa possuem a uretra encurtada em relação a uretra masculina, e sofrem muitas alterações hormonais durante a gravidez (Quadro 2). 


\section{Revista Eletrônica Acervo Saúde / Electronic Journal Collection Health | ISSN 2178-2091}

Quadro 2 - Caracterização dos artigos segundo autor, ano de publicação, base de dados proveniente, e principais fatores de risco de infecção do tratourinário, $\mathrm{n}=15$.

\begin{tabular}{|c|c|c|c|}
\hline Autores e ano de publicação & $\begin{array}{l}\text { Base de } \\
\text { dados } \\
\text { proveniente }\end{array}$ & Principais fatores de risco de infecção do tratourinário & Nível de evidência \\
\hline (VETTORE MV, et al., 2013) & BVS & $\begin{array}{l}\text { Um dos principais fatores de risco de infecção do tratourinário são as bactérias } \\
\text { circunvizinhas da região genital que entram na uretra e podem causar infecções. }\end{array}$ & $2 \mathrm{C}$ \\
\hline $\begin{array}{l}\text { (NASCIMENTO WL, et al., } \\
\text { 2015) }\end{array}$ & BVS & $\begin{array}{l}\text { São fatores de risco para infecção do tratourinário a falta de higiene na região intima } \\
\text { ou o excesso dela. }\end{array}$ & $2 \mathrm{C}$ \\
\hline (BARROS SK, et al., 2013) & BVS & $\begin{array}{l}\text { A anatomia da uretra feminina e uso de cateteres vesicais são fatores de risco para } \\
\text { infecções no tratourinário. }\end{array}$ & $2^{\mathrm{a}}$ \\
\hline (IZAIAS EM, et al., 2014) & BVS & $\begin{array}{l}\text { O uso de cateter aumenta os riscos de desenvolvimento de infecções no trato urinário } \\
\text { dos pacientes. }\end{array}$ & $2^{\underline{a}}$ \\
\hline (PAULA MLA, et al., 2016) & BVS & $\begin{array}{l}\text { As infeções no tratourinário são atribuídas em grande parte a pessoas que fazem } \\
\text { práticas sexuais sem camisinha. }\end{array}$ & $3^{\underline{a}}$ \\
\hline (APOLINÁRIO TA, et al., 2016) & BVS & A resistência a antibióticos são fatores de risco para infecções no trato urinário. & $2^{\mathrm{a}}$ \\
\hline $\begin{array}{l}\text { (FLORES VGT, FERREIRA } \\
\text { JÚNIOR MA, 2012) }\end{array}$ & BVS & $\begin{array}{l}\text { O uso do cateter vesical de demora é um fator que contribui para a instalação de } \\
\text { infeçõos no tratourinário, além dessas infeçõos serem mais prevalentes no sexo } \\
\text { feminino devido ao encurtamento anatômico da uretra. }\end{array}$ & $2 \mathrm{C}$ \\
\hline (TORRES GV, et al., 2010) & BVS & $\begin{array}{l}\text { O uso de cateteres vesicais de demora é um dos principais causadores de infecções } \\
\text { no tratourinário quando manejados de maneira incorreta. }\end{array}$ & $2 \mathrm{C}$ \\
\hline (MAZZER M, SILVA JO, 2010). & BVS & $\begin{array}{l}\text { A gravidez é um fator de risco ao aparecimento de infecções do trato urinário, devido } \\
\text { às mudanças fisiológicas, mecânicas e hormonais que ocorrem nesse período. }\end{array}$ & $2 \mathrm{C}$ \\
\hline (CARVALHO FLO, et al., 2018) & BVS & $\begin{array}{l}\text { São fatores de risco para infecções urinarias aumento da idade, urina com } \mathrm{pH} \\
\text { alcalino, infecção genital, e má higienização das regiões perianal e vaginal. }\end{array}$ & $2 \mathrm{C}$ \\
\hline (BORGES AA, et al. 2014) & PubMed & $\begin{array}{l}\text { São fatores de risco para infecções urinárias a falta de higiene adequada nas roupas } \\
\text { intimas e na região genital, e o não uso de preservativos nas atividades sexuais. }\end{array}$ & $2^{a}$ \\
\hline $\begin{array}{l}\text { (CASTRO FILHO CAS, et al., } \\
\text { 2013) }\end{array}$ & PubMed & $\begin{array}{l}\text { Um dos principais fatores de risco para infecções no tratourinário são as práticas } \\
\text { sexuais desprotegidas. }\end{array}$ & 3B \\
\hline (FERREIRA RC, et al., 2016) & PubMed & $\begin{array}{l}\text { A diabetes mellitus e a hiperglicemia são fatores de risco para infecções urinarias, pois } \\
\text { podem favorecer o desenvolvimento das bactérias. }\end{array}$ & 3B \\
\hline (SANTOS CC, et al., 2019) & PubMed & $\begin{array}{l}\text { Infecções sexuais ou genitais tais como a candidíase são fatores de risco para } \\
\text { infecções no trato urinário. }\end{array}$ & 3B \\
\hline (PIGOSSO YG, et al., 2016) & PubMed & $\begin{array}{l}\text { A gravidez é um fator de risco para o desenvolvimento de infecções no trato urinário, } \\
\text { pois altera o fluxo urinário. }\end{array}$ & $2 \mathrm{C}$ \\
\hline
\end{tabular}

Fonte: SILVA PPA, et al., 2020. Baseado em dados extraídos de BVS e PubMed. 
As infecções do trato urinário apresentam múltiplas causas e fatores de risco. Segundo Vettore MV, et al. (2013) o trata urinário é normalmente estéril e possui resistência à colonização de patógenos, apesar do contato frequente da uretra distal com bactérias dispostas externamente na região genital humana. O principal mecanismo de defesa fisiológico do aparelho urinário é a micção, onde a urina leva para fora do trato urinário às bactérias circunvizinhas da região genital podem entrar em contato com a região interna da uretra e causar infecções. Corroborando com esse fato, Borges AA, et al. (2014) expuseram que a maioria das causas de ITU mais comuns estão relacionadas as bactérias, onde estes patógenos ascendem a uretra para a bexiga, ou ascendem do ureter para os rins. Além disso, são fatores de risco a falta de higiene adequada nas roupas intimas e na região genital, e o não uso de preservativos nas atividades sexuais.

De acordo com Nascimento WL, et al. (2015) a higiene é um fator de risco de ITU, estando essas infecções relacionadas a falta dela ou seu excesso, assim os autores abordam que a falta de higiene intima nos homens propicia um aumento de bactérias ao redor da glande, que podem atingir o canal uretral masculino e contaminar todo sistema urinário dependendo do número de bactérias. Todavia o excesso de higiene, principalmente nas mulheres, altera o $\mathrm{pH}$ da área genital, e as bactérias invasoras podem se difundir para 0 trato urinário causando infecções.

Para Barros SK, et al. (2013), outro fator de risco para infecção urinaria está relacionada ao comprimento da uretra, que no sexo feminino é menor que no sexo masculino, e pode propiciar a colonização de patógenos devido à proximidade do canal uretral com o exterior, facilitando ainda mais a entrada de microrganismos na bexiga, e o uso de cateteres vesicais que podem levar microrganismos patógenos diretamente para o trato urinário quando não se é seguido corretamente o procedimento de sondagem.

Seguindo essa vertente, Izaias EM, et al. (2014) discorreu também que o uso de cateter aumenta os riscos de desenvolvimento de infecções no trato urinário dos pacientes, tal fato ocorre pela introdução de um componente não orgânico na uretra que pode estar contaminado ou ter se contaminado durante a técnica de passagem de sonda, e, além disso, repetidas introduções de cateteres urinários, ou seu uso por vários dias tornam-se meios de colonização de microrganismos, especialmente bactérias que podem causa infecções no trato urinário dos pacientes.

Já Castro Filho CAS, et al. (2013) relacionou como fator de risco para ITU, as práticas sexuais desprotegidas, pois pessoas que não utilizam camisinha além do risco de contraírem infecções sexualmente transmissíveis (IST), tem maior chance de contraírem infecções no trato urinário devido as bactérias ou fungos provenientes das mucosas contaminadas dos parceiros sexuais. Reforçando esse fator, Paula MLA, et al. (2016) relataram que mais da metade das pessoas que já fizeram sexo sem camisinha contraíram infecção urinaria, e a pratica sexual mais relacionada ao aparecimento dessas infeções é o sexo anal sem preservativo, todavia existia uma taxa significativa de infecções no trato urinário em pessoas que fizeram sexo vaginal e oral sem preservativo.

Outro fator de risco para ITU foi apontando por Apolinário TA, et al. (2016) foi a resistência a antibióticos, pois devido ao fácil acesso a esses fármacos e ao consumo desenfreado, o organismo de um paciente submetido a doses errôneas de antibióticos frequentemente pode deixar as bactérias resistentes, e estas podem atacar as defesas do corpo com mais facilidades causando uma serie de malefícios a saúde, entre eles as infecções urinarias.

\section{Principais sintomas e métodos diagnósticos para identificar as infecções no trato urinário}

Quanto aos sintomas mais comuns de uma infecção no trato urinário Apolinário TA, et al. (2016) citaram a dor na região pélvica, especialmente em mulheres, vontade constante de urinar, pouca quantidade de urina no ato miccional, ardência ao urinar, dor na região de flancos e incontinência urinaria. A dor ao urinar pode ser proveniente de quadros de desidratação devido a micção continua, ou alguma outra bactéria que não esteja acoplada na bexiga ou na uretra. Outros sintomas menos frequentes podem surgir como urina escura, presença de sangue na urina, dor na região retal, e alguns sinais ou sintomas podem não se correlacionar à localização da infecção do trato urinário causando confusão no paciente, isso pode ocorrer devido considerável sobreposição a outras condições fisiológicas como gravidez e período menstrual nas mulheres (NASCIMENTO WL, et al., 2015). 
Pessoas com ITU podem ter ainda sintomas relativos a infecções no geral, como febre, mal-estar, calafrio, náuseas, vômitos, e em alguns casos menos frequentes discreta rigidez no quadrante inferior abdominal e queixa de dor a percussão costovertebral. A ausência de sinais e sintomas na infecção do trato urinário constitui a sua forma assintomática, e se apresenta tipicamente em pacientes com diabetes, idosos e gestantes, todavia a ausência de sintomatologia pode acarretar em complicações clínicas a estes pacientes (CASTRO FILHO CAS, et al., 2013).

Corroborando com esses achados, Magalhães SR et al. (2014) complementaram que as complicações de infecção urinária podem ter variados sinais e sintomas conforme seu tipo, todavia a uma constância nos casos de queixas de cólicas renais, febre alta, hematúria e algia irradiante no sentido dos membros inferiores e abdominal. Para tal, é importante que os profissionais de saúde conheçam todos os sintomas de ITU, inclusive os sinais e sintomas menos comuns, para combater a infecção antes que ela acarrete mais prejuízos à saúde e ao conforto do paciente.

Quanto aos diagnostico de uma infecção no trato urinário, esse é realizada por urologistas, ginecologista e médicos clínico geral. O exame de urina, compreendendo o exame de urina tipo 1 e urocultura, é o principal exame diagnóstico de infeções urinarias. O exame de urina tipo 1 analisa sinais de infecção no conteúdo urinário, tais como presença de leucócitos e traços de sangue, e é realizado com a primeira urina do paciente no dia, que pode ser coletada na residência do paciente (RAMOS GC, et al., 2016).

No exame de urina tipo 1, a urina aleatória, em qualquer fase do dia, também pode solicitada em caso de urgências, sendo útil para detectar anormalidades muito evidentes, todavia, seu resultado pode ser alterado pela ingestão de alimentos e até mesmo pela realização de atividades físicas. As mulheres não devem realizar o exame durante o período menstrual, pois a presença de sangue pode influenciar o resultado do teste, prejudicando a visualização da urina no microscópico (HACHUL M, SILVA DB, 2014).

Já na urocultura, uma amostra da urina do paciente é reservada para a cultural em placas de petri para a formação da colônia da bactéria que coloniza o trato urinário do paciente, tal método é eficiente para análise da espécie da bactéria, e consequentemente na escolha do melhor medicamento para combatê-la, todavia o seu resultado é demorado, podendo contribuir para a proliferação bacteriana no trato urinário do paciente e surgimento de possíveis complicações, por isso é recomendado que esse exame seja associado a outro mais rápido, como o exame de urina tipo 1, para o início precoce do tratamento (SANTOS CC, et al., 2019).

Reforçando essas informações, Schenkel DF, et al. (2014) enfatizaram que o uso do exame de urocultura é fundamental no combate a resistências bacterianas devido ao uso errôneo de antibiótico, uma vez que por meio desse exame é possível ter um plano terapêutico adequado para combater o patógeno, e assim evitar um dos fatores de risco para ITU. Além disso, tanto nos exames de urina tipo 1 e de urocultura, os pacientes que forem coletar a urina devem ser orientados pelos profissionais de saúde quanto a realização da higiene da região genital apenas com água e sabão para não alterar os resultados dos exames.

Magalhães SR, et al. (2014) citaram a cistoscopia como método diagnostico, que é um exame que analisa a porção interior da bexiga e da uretra, a fim de identificar a causa da infecção, e assim servir para identificação de alterações na bexiga que podem ser a causa de infecções urinarias recorrentes. A cistoscopia auxilia ainda no diagnóstico de outras patologias no sistema urinário, tais como cancro da bexiga, inflamação ou litíase, porém devido ao alto custo de sua realização o torna menos requisitado para o diagnóstico de infecção do trato urinário em comparação com os outros tipos de exames.

\section{Tratamentos para as infecções no trato urinário}

De acordo com Barros SK, et al. (2013), o tratamento para infecção no trato urinário geralmente é farmacológico, sendo utilizados antibióticos de acordo com a espécie do patógeno, mas ocasionalmente são indicadas intervenções cirúrgicas para drenar abscessos, corrigir anomalias estruturais de base ou aliviar a obstrução da uretra ou ureteres. O tratamento de infecções urinárias varia muito de acordo com o tipo de cada infecção e sua gravidade também, alguns profissionais podem prescrever além dos antibióticos, analgésicos para alivio dos sintomas de disúria. 
Tratamentos caseiros não tem efeito para sessar a infecção urinaria, todavia, alguns podem ser utilizados para aliviar os sintomas, mas o paciente deve se informar com o médico se realmente pode fazê-lo, uma vez que alguns tratamentos caseiros podem ser nocivos à saúde. Dentre os tratamentos caseiros mais indicados estão o uso de chás, tais como o de manjericão, carqueja e de aroeira que tem leve efeitos anti-bacteriologico, e sucos de cranberry e melancia, caso o paciente não tenha alguma condição de saúde que possa ser piorada com o excesso dessas soluções, como por exemplo diabetes ou hipertensão arterial (CARVALHO FLO, et al., 2018).

Quanto aos tratamentos farmacológicos, a escolha dos antibióticos pelos médicos além de levar em conta a espécie da bactéria, deve ser investigado se o paciente possui alergia a algum tipo de antibioticoterapia, adesão do paciente, disponibilidade e custos dos antibióticos, e tolerância do paciente e provedor para o risco de falha do tratamento. Algum fármaco utilizado para o tratamento de infecção urinaria são amicacina, amoxicilina, cefalexina, ciprofloxacino, doxiciclina, e norfloxacino, cada um desses fármacos são prescritos de acordo com a necessidade terapêutica dos pacientes (NASCIMENTO WL, et al., 2015).

A amicacina é indicada no tratamento a curto prazo de infecções graves causadas por espécies sensíveis de bactérias do tipo gram-negativas, que geralmente são as bactérias mais causadoras de infecção urinaria, todavia pode causar efeitos teratogênicos quando utilizado por gestantes, e as lactantes devem suspender a amamentação até que 0 tratamento tenha sido finalizado, pois substancias desse fármaco podem se difundirem ao leite materno e serem repassadas as crianças (HACHUL M, SILVA DB, 2014).

A amoxicilina é um antibiótico da família das penicilinas, e possui ampla atividade contra bactérias. Pode ser usada em associação com ácido clavulânico, pois este possui a capacidade de inativar a betalactamase, que é uma substancia produzida por algumas espécies de bactérias provocando resistência ao tratamento com penicilinas. A posologia desses fármacos deve ser seguida conforme a indicação médica para evitar efeitos tóxicos hepatológicos (BARROS SK, et al., 2013).

Outra alternativa farmacológica para o tratamento de infecção no trato urinário é o norfloxacino pois este é um agente bactericida de amplo espectro indicado para o combate de uma gama de infecções causadas por bactérias, mas é contraindicado para as crianças e jovens menores de 14 anos, e apesar de não ter sido encontrado traços do fármaco no leite materno, seu uso é restringido durante a gravidez e a amamentação, exceto sob orientação médica (SCHENKEL DF, et al., 2014).

A cefalexina é comumente utilizada no tratamento de infecções do trato urinário, todavia é indicando que se realize de testes de sensibilidade à cefalexina e culturas apropriadas do microrganismo causador, antes de iniciar o tratamento com esse fármaco para prevenir possível resistência bacteriana a medicação. Já o cloridrato de ciprofloxacino tem ação de bloquear determinadas enzimas de bactérias que têm um papel fundamental na reprodução bacteriana, esse antibiótico não deve ser tomado com laticínios ou bebidas enriquecidas com minerais pois podem atrapalhar sua absorção (IZAIAS EM, et al., 2014).

A doxiciclina é indicada para o tratamento de infecções no trato urinário causadas por microrganismos gram-negativos e gram-positivos quando os testes bacteriológicos indicarem suscetibilidade adequada ao uso do fármaco. Tal fármaco é bastante utilizado por pessoas que tem alergia a penicilina, pois possui ação semelhante e menor intercorrência de reações alérgicas (CASTRO FILHO CAS, et al., 2013).

É importante que no tratamento de ITU os pacientes não se automediquem, pois devido ao uso desenfreado ou incorreto de antibióticos, as bactérias sofrem mutações que as tornam resistentes aos mecanismos de ação dos fármacos, tornando mais difícil de encontrar o tratamento medicamentoso que faça efeito. Assim, é aconselhável que em caso de suspeita de infeção urinaria, as pessoas procurem assistência médica, e realizem o exame de urocultura para indicar o tipo de agente etiológico causador da infecção e qual a melhor medicação para combatê-lo (DIAS IOV, et al., 2015).

Um grande problema relacionado ao tratamento de infecção urinaria é que mesmo os pacientes utilizando os fármacos prescritos pelo médico, eles não tomam as doses adequadas, ou deixam de tomar o medicamento quando os sintomas de infecção no trato urinário desaparecem, e isso pode causar recorrência da infecção urinária (PAULA MLA, et al., 2013). 
A não adesão ao tratamento pode contribuir para a progressão da infecção ou a sua exacerbação, pode levar ao fracasso terapêutico, aumentar os custos com o tratamento e se fator de risco para a instalação de resistência bacteriana (PAULA MLA, et al., 2013).

\section{CONSIDERAÇÕES FINAIS}

As infecções do trato urinário são bastante comuns entre a população, e podem causar maiores complicações a saúde quando não tratadas adequadamente, assim conhecer seus fatores de riscos é importante para realizar medidas que previnam a sua ocorrência. Os principais fatores de risco evidenciados foram o uso de cateteres vesical, as práticas sexuais desprotegidas, infecção genital previa, resistência a antibióticos, falta ou excesso de higiene nas áreas genitais, anatomia da uretra, hiperglicemia e alterações hormonais. Os métodos diagnósticos são comumente realizados através dos sinais e sintomas apresentados pelos pacientes, e confirmado através de exames, como o exame de urina tipo 1 e urocultura, assim o tratamento medicamentoso dependerá da espécie de patógeno identificado no diagnóstico.

\section{REFERÊNCIAS}

1. APOLINÁRIO TA, et al. Prevalência de infecção urinária e resistência a antimicrobianos em um grupo de gestantes. Revista Cientifica da Faminas, 2016; 10(2).

2. BARROS SK, et al. Infecção do trato urinário relacionada ao cateter: perfil de sensibilidade antimicrobiana. Revista da Rede de Enfermagem do Nordeste, 2013; 14(5).

3. BORGES AA, et al. Infecção Urinária em Gestantes Atendidas em um Laboratório Clínico de Goiânia-Go Entre 2012 e 2013. Revista de Ciências Ambientais e Saúde, 2014; 41(3).

4. CARVALHO FLO, et al. Infecção urinária de repetição e os aspectos gerais, microbiológicos e imunológicos associados à saúde da mulher. Revista de Saúde ReAGES, 2018; 1(3): 24-30.

5. CASTRO FILHO CAS, et al. Estudo do perfil de resistência antimicrobiana das infecções urinárias em mulheres atendidas em hospital terciário. Revista Brasileira de Clínica Medica, 2013; 11(2): 2013.

6. DIAS IOV, et al. INFECÇÃO DO TRATO URINÁRIO EM PACIENTES AMBULATORIAIS: prevalência e perfil de sensibilidade aos antimicrobianos em estudo realizado de 2009 a 2012. Revista de Saúde de Santa Maria, 2015; 41(1): 209-218.

7. ERCOLE FF, et al. Revisão integrativa: evidências na prática do cateterismo urinário intermitente/demora. Revista Latino-Americana de Enfermagem, 2013; 21(1): 459-468.

8. FERREIRA RC, et al. Perfil de infecção urinária associada à taxa de glicemia alterada. RBAC, 2016; 48(4): 346-51.

9. FLORES VGT, FERREIRA JÚNIOR MA. Fatores de risco para infecção do trato urinário dos pacientes submetidos ao procedimento de cateterismo vesical de demora e suas implicações para a enfermagem. Revista Científica Linkania Júnior, 2012; 2(2).

10. HACHUL M, SILVA DB. Infecção do trato urinário. Revista brasileira de medicina, 2013; 70(12).

11. IZAIAS EM, et al. Custo e caracterização de infecção hospitalar em idosos. Ciência \& Saúde Coletiva, 2014; 19(3): 3395-3402.

12. MAGALHÃ̈ES SR, et al. EVIDÊNCIAS PARA A PREVENÇÃO DE INFECÇÃO NO CATETERISMO VESICAL: revisão integrativa. Journal of Nursing UFPE/Revista de Enfermagem UFPE, 2014; 8(4).

13. MAZZER M, SILVA JO. Causas e riscos de infecção urinária em gestantes. Revista Multidisciplinar da Saúde, 2010; 2(4): 62-70.

14. NASCIMENTO WL, et al. Infecção do trato urinário em gestantes usuárias do Sistema Único de Saúde. Ensaios e Ciência: C. Biológicas, Agrárias e da Saúde, 2015; 16(4).

15. OXFORD. 2009. In: OXFORD CENTRE FOR EVIDENCE BASED MEDICINE: levels of evidence. Disponível em: http://www.cebm.net/oxford-centre-evidence-based-medicine-levels-evidence-march-2009. Acesso em: 27 out. 2020.

16. PAULA MLA, et al. Infecção do trato urinário em mulheres com vida sexual ativa. Jornal brasileiro medico, 2016; 103(2): 1423-1431.

17. PIGOSSO YG, et al. Infecção do trato urinário em gestantes: incidência e perfil de suscetibilidade. Acta Biomedica Brasiliensia, 2016; 7(1): 64-73.

18. RAMOS GC, et al. Prevalência de infecção do trato urinário em gestantes em uma cidade no sul do Brasil. Revista Saúde, 2016; 42(1):173-178.

19. SANTOS CC, et al. Prevalência de infecções urinárias e do trato genital em gestantes atendidas em Unidades Básicas de Saúde. Revista de Ciências Médicas, 2019; 27(3): 101-113.

20. SCHENKEL DF, et al. Etiologia microbiana e suscetibilidade de infecções do trato urinário comunitário durante a gravidez no sul do Brasil. Revista Brasileira de Ginecologia e Obstetrícia, 2014; 36(3): 102-106.

21. TORRES GV, et al. Cateterismo vesical de demora como fator de risco para infecção do trato urinário: conhecimento da equipe de enfermagem de unidade de terapia intensiva. Revista enfermagem UFPE, 2010; 4(2): 1-9.

22. VETTORE MV, et al. Avaliação do manejo da infecção urinária no pré-natal em gestantes do Sistema Único de Saúde no município do Rio de Janeiro. Revista Brasileira de Epidemiologia, 2013; 16(3): 338-351. 